\title{
PROFESSIONAL DEVELOPMENT IN REMOTE SENSING FOR COMMUNITY COLLEGE INSTRUCTORS
}

\author{
J. E. Allen ${ }^{\mathrm{a} *}$, and C. Cruz \\ ${ }^{a}$ Sr. Technical Specialist, Sigma Space Corp., 4600 Forbes Blvd., Lanham, MD 20706 - Jeannette.E.Allen@nasa.gov \\ bDivision Chair, Park Management, West Valley College, 14000 Fruitvale Ave., Saratoga, CA 95070 - chris.cruz@westvalley.edu
}

KEY WORDS: Community College; Professional Development, Training

\begin{abstract}
:
The ingredients for the highly successful, ongoing educator professional development program, "Integrated Geospatial Education and Technology Training-Remote Sensing (iGETT-RS)" came into place in 2006 when representatives of public and private organizations convened a two-day workshop at the National Science Foundation (NSF) to explore issues around integrating remote sensing with Geographic Information Systems (GIS) instruction at two-year (community and Tribal) colleges. The results of that 2006 workshop informed the shape of a grant proposal, and two phases of iGETT-RS were funded by NSF's Advanced Technological Education Program (NSF DUE \#0703185, 2007-2011, and NSF DUE \#1205069, 2012-2015). 76 GIS instructors from all over the country have been served. Each of them has spent 18 months on the project, participating in monthly webinars and two Summer Institutes, and creating their own integrated geospatial exercises for the classroom. The project will be completed in June 2015. As the external evaluator for iGETT expressed it, the impact on participating instructors "can only be described as transformative." This paper describes how iGETT came about, how it was designed and implemented, how it affected participants and their programs, and what has been learned by the project staff about delivering professional development in geospatial technologies for workforce preparedness.
\end{abstract}

\section{INTRODUCTION}

Community colleges provide fertile ground for Landsat education and workforce training. According to the American Association of Community Colleges, they serve close to half the undergraduate students in the United States, "providing open access to postsecondary education, preparing students for transfer to 4-year institutions, providing workforce development and skills training, and offering noncredit programs." Community colleges are also very well positioned to increase diversity in the nation's workforce. 56\% of all Hispanic students, $48 \%$ of all Black students, $59 \%$ of all Native American students, and $44 \%$ of Asian/Pacific Islander students attend a two-year public institution.

Landsat - the world's longest record of Earth's land surface-is invaluable for workforce development and education given its superior quality, consistency through time, multi-faceted utility, and accessibility for no charge to users. Landsat instruments provide learning windows into remote sensing in general because they observes the land itself on which we live, so the data are tangibly linked to peoples' personal experiences and sense of space.

In an endeavor to marry the opportunity afforded by community colleges and two-year Tribal colleges with the geospatial skills needed to exploit the power of Landsat data, the National Science Foundation (NSF) funded the instructor professional development

This material is based upon work supported by the National Science Foundation under Grant No. DUE ATE 1205069. Any opinions, findings, and conclusions or recommendations expressed in this material are those of the author and do not necessarily reflect the views of the National Science Foundation. program, "Integrated Geospatial Education and Technology Training (iGETT)," 2007-2015. iGETT was designed to instruct, support, and expand a community of educators who could give students a solid foundation in remote sensing, particularly integrated with Geographic Information Systems (GIS). This paper describes how iGETT came about, how it was designed and implemented, how it affected participants and their programs, and what has been learned by the project staff about delivering professional development in geospatial technologies for workforce preparedness.

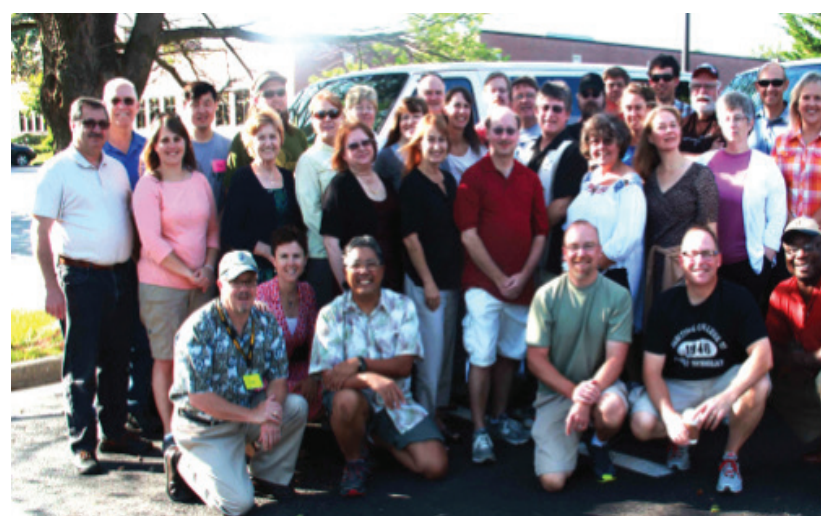

Figure 1. iGETT's Cohorts 3 and 4 pose with staff in June 2014 at Northern Virginia Community College where participants learned to analyze and integrate federal land remote sensing data with Geographic Information Systems (GIS) to solve specific problems of societal concern. 


\section{PROGRAM INSPIRATION, DEVELOPMENT AND DESIGN}

Geography provided the bridge between federal remote sensing and GIS for the iGETT public-private education partnership. Geography is a broad discipline concerned with both physical and human environments. At its core is the study of landscapes and their features. What is the nature of these features and why are they where they are? What is their sphere of influence? What do they affect and what affects them? What patterns can be discerned across landscapes and what do the patterns mean for the lives of people and ecosystems? How can we use our understanding of how and why such patterns are changing to predict future trends of societal concern? These are some of the questions also asked by remote sensing scientists, for whom every data point from a satellite mission must be identified in terms of location.

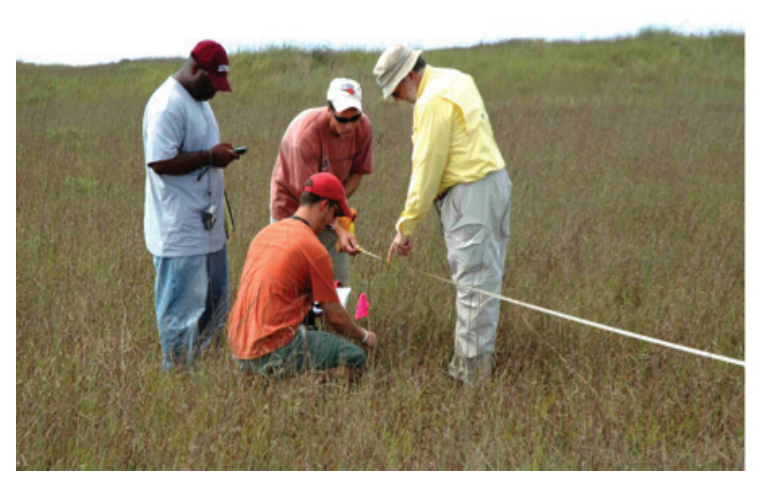

Figure 2. Members of iGETT Cohort 2 use GPS units in a ground based Exercise in Landsat data validation.

iGETT was conceived in 2005 when the question was asked, could two-year colleges serve as venues for delivery of professional development remote sensing data analysis? Around that time GIS had made inroads into two-year colleges. About 400 two-year colleges had GIS courses, but very few offered remote sensing. Bringing remote sensing to GIS programs seemed to be an idea worth pursuing. Geography and remote sensing educators convened a twoday workshop at NSF in August 2005 to explore this question. NSF's Advanced Technological Education (ATE) hosted and partially funded the workshop. Additional funding was provided by Esri, NASA, and USGS. The workshop, Integrating Geographic Information Systems and Remote Sensing: Technical Workforce Training at Two-Year Colleges, brought together professionals from different domains of work who shared an interest in geospatial workforce development. 53 participants represented academia, industry, professional associations, and both local and federal government agencies to (1) discuss if and how geospatial technology training at two-year colleges could address workforce needs; and (2) recommend ways to structure and implement effective two-year programs that integrate geospatial technologies.

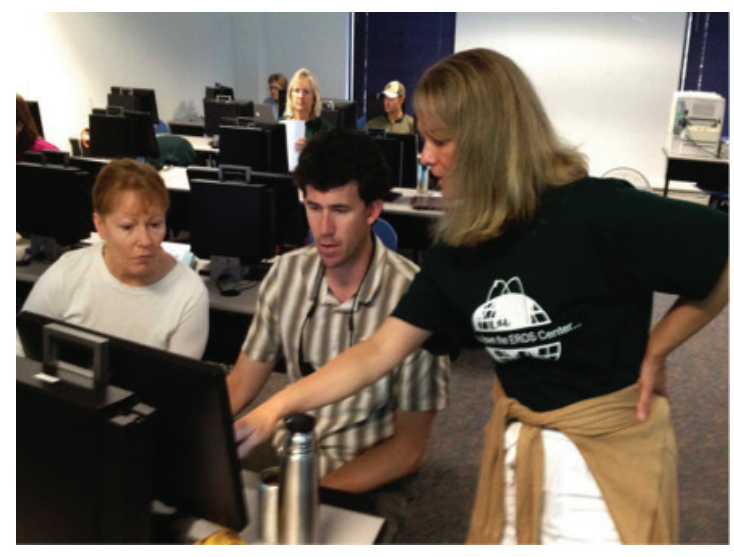

Figure 2b. Members of iGETT Cohort 3 help each other with remote sensing analysis (at right).

The approach of bringing together people from disparate workforce domains to investigate an issue of shared interest proved an effective model for moving the inquiry forward. Over the two days of the workshop, participants reached clear agreement that twoyear colleges should be able to assume a strong role in training entry-level geospatial technologists; that remote sensing was a critical curriculum area for two-year geospatial technology programs; and that the curriculum should foster problem-solving and communication skills as well as remote sensing. Obstacles to establishing effective programs were identified as a lack of trained faculty; the high costs of hardware and software; unfamiliarity with geospatial career prospects by both students and college administrators; articulation problems with four-year institutions; and the lack of understanding by many local employers of how geospatial technologists could support their operations. Recommended implementation strategies focused on ways to overcome these obstacles by recruiting and training faculty, building internal college support, making and utilizing connections with local businesses and agencies that use geospatial technology, and marketing the programs on campuses and in their local communities. The full report from this 2005 workshop at NSF is available upon request to the authors.

Based on results of the 2005 workshop, the education collaborators submitted two successful proposals to NSF ATE: iGETT-1 (20072011) and then iGETT-Remote Sensing (2013-2015). The primary goal of each project was to increase the number of entry-level workers who could use remote sensing for problem solving in areas of concern to their communities. The second phase of the project, iGETT-RS, was enhanced by the staff's experience and lessons learned from the first phase, iGETT-1. The staff were also able to include iGETT-1 participants in leadership roles for iGETT-RS. Christopher Cruz, a member of Cohort 1, became a Co-PI for iGETT-RS, and the staff engaged several other iGETT-1 graduates to help with instruction for participants during Summer Institutes and monthly project webinars. 


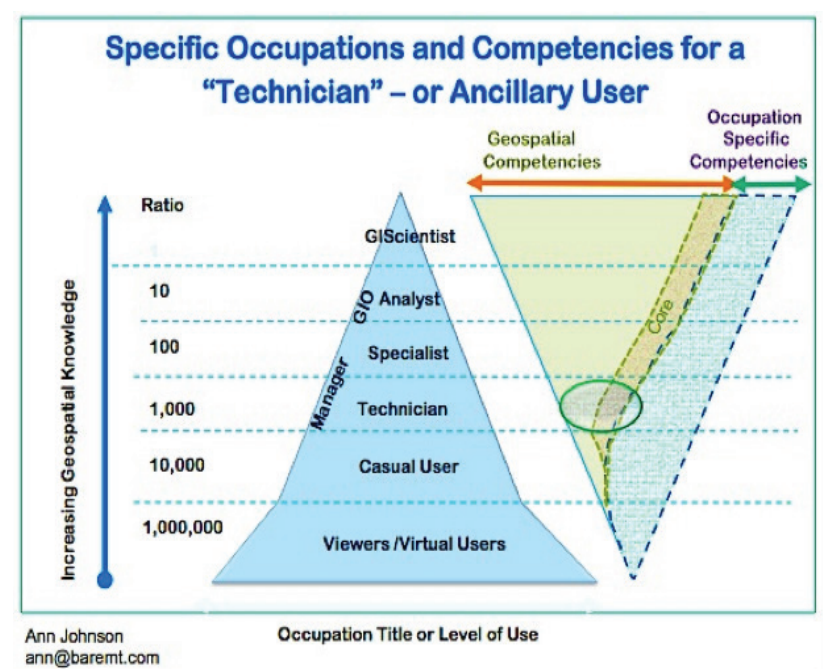

Figure 3. This schematic illustrates the role of the introductory level remote sensing technician within the workforce domain of geospatial technology, a role that has come into being only in the last few years with the advent of no-cost, easily-accessed land remote sensing data. An oval in the upside-down triangle at right indicates the level of competency targeted by the iGETT project.

Leading iGETT as Principal Investigator has been Osa Brand, National Council for Geographic Education. Co-Principal Investigators have been Jeannie Allen, Sigma Space Corp. at NASA Goddard Space Flight Center (co-author); Ann Johnson, GeoTech Center; Rachel Headley, Black Hills State University (with USGS Land Remote Sensing until October 2013); Christopher Cruz, West Valley College instructor and U.S. National Park Service (co-author); and Laura Peyton Rocchio, Science Systems and Applications, Inc.

iGETT has served 60 two-year college instructors (including six Tribal college instructors); eight high school instructors; and eight professors from four-year institutions (including two from Tribal colleges). Through these participants approximately 6,000 students have been reached with remote sensing instruction. At least 35 courses have been enhanced with remote sensing and 20 new courses have been developed, with the course accomplishments of the project's last cohort of participants yet to be counted.

iGETT participants came from a national pool of applicants representing a variety of disciplines: agriculture, biology, computer science, engineering, geography, physical science and social science; and they represented a range of workforce-based programs from park management to applied technology. During the application periods for each of the four cohorts, consistently more than twice as many applications were received as the project could accommodate. Applicants for Cohorts 3 and 4 included a higher proportion of high school and four-year school instructors than did the applicant pool for Cohorts 1 and 2, which would appear to indicate potential for expanding the project to serve more instructors at those levels in the future.
Applicants were required to submit not only a completed application form documenting experience in teaching GIS, but also a letter from a department chair or other administrator agreeing to cover travel costs to two Summer Institutes which were held in Texas, South Dakota and Virginia in different years. The latter requirement was intended to ensure that each applicant's home institution would support implementation of project results. Applicants whose institutions could not provide travel funds were welcome to seek other funding or to cover travel costs themselves. (All other costs were covered by the project.) A few applicants chose this option.

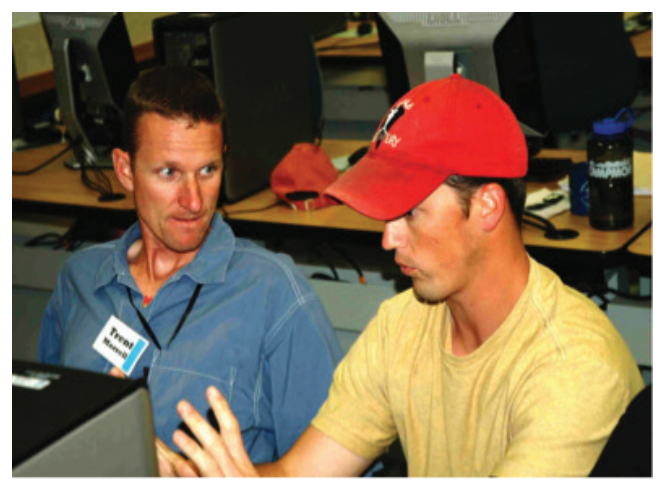

Figure 4. "Words cannot begin to describe the impact this... experience has had on me as an instructor, a geographer and geoscientist, and as a person." Trent Morrell, Laramie County Community College (WY) here with Adam Dastrup, Salt Lake Community College (UT).

The iGETT staff enlisted the oversight of an Advisory Board that has brought expertise from both government and private organizations: Bill Hodge, City of Midland, TX; Torry Johnson, NASA; Jon Dykstra, MDA Information Systems, Inc.; Joseph J. Kerski, Esri; Marguerite Madden, University of Georgia; Rich Serby, GeoSearch, Inc.; Jeffrey M. Young, LizardTech; R. Maxwell Baber, U.S. Geospatial Intelligence Foundation; and Rodney D. Jackson County Community College, NC. The Board has met by webinar twice per year. Board members have approved the process and results of the project, providing guidance particularly on topics to be covered during the Institute.

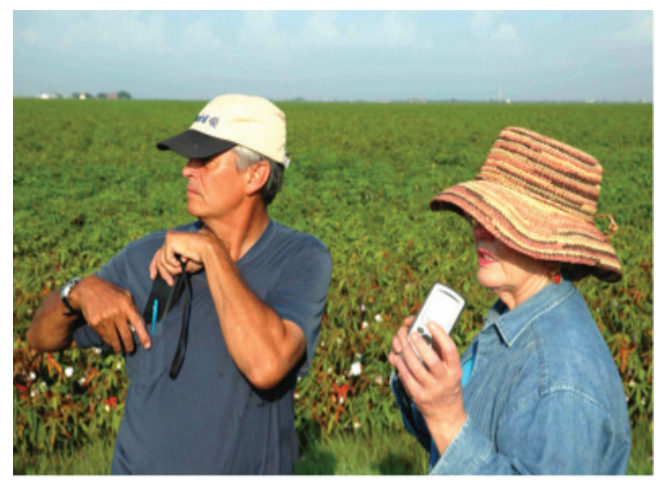

Figure 5. Douglas Crebs, Stone Child College, and Barbara DuFrain, Delmar College, learn how to use a Global Positioning System (GPS). Crebs commented, "The training that was provided... was fantastic. One of the most professional and rigorous trainings I have been involved with..." 
Further support came from the American Society for Photogrammetry and Remote Sensing (ASPRS). The Society provided workforce professionals to review the curriculum materials produced by the participants. ASPRS also donated a one-year membership to each iGETT participant.

During the Summer Institutes, iGETT participants learned fundamental physics and technology of land remote sensing and how to download, analyze and integrate federal land remote sensing data (Landsat, MODIS and ASTER) with GIS to solve problems in agriculture, disaster management, forestry, land use/land cover change, natural resources management, human health, and urban growth. An important result of iGETT has been the creation and fostering of a new community upon which participants now rely. Several participants have also taken on new leadership roles in national and regional geospatial education, securing grants to bring the training to others. iGETT has given two-year college instructors enhanced confidence and new practical tools.

Each iGETT participant spent 18 months with the project involved in the following activities:

- two online courses, one a GIS refresher course and one introduction to remote sensing, completed prior to the first Summer Institute;

- two Summer Institutes (in person) at resource-rich private and federal locations;

- remote sensing analysis and GIS software;

- monthly webinars during the academic years.

Participants received stipends upon completion of their deliverables (see below, Participant Deliverables):

- $\$ 900$ for successful completion of the two Summer Institutes and $\$ 400$ during the intervening academic year for developing instructional materials;

- reimbursement of up to $\$ 100$ for local/regional outreach activities;

- opportunities to compete for two awards of up to $\$ 1,300$ each to cover costs of presenting at national-level professional conferences.

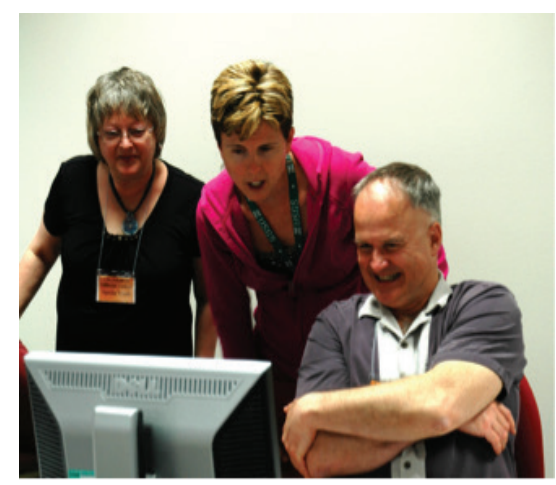

Figure 6. Debbie Stevens (IA), Rachel Headley (SD) and Hector Douglas (AK) in the computer lab

The two online courses proved extremely helpful in ensuring that all participants were aligned in terms of their GIS skills before they came to the Summer Institutes. The online remote sensing course was the tutorial, "Fundamentals of Remote Sensing," provided by the Canada Centre for Remote Sensing (http://www.nrcan.gc.ca/ earth-sciences/geography-boundary/remote-sensing/fundamentals/1430). Participants had to pass post-course tests in order to be accepted for the Summer Institutes. By far most participants reported that these courses were worthwhile.

The first Summer Institutes focused on participants' technical skills. The Institutes combined hands-on lab activities; presentations and instruction by iGETT staff; presentations by NASA and USGS scientists; and field work on using the Alta II Reflectance Spectrometer and on mapping a pixel. Participants learned about:

- ways in which people use remote sensing for research and operational activities

- the electromagnetic spectrum, converting light to digital numbers, and spectral signatures

- spectral, radiometric, spatial and temporal resolutions

- finding and downloading data from USGS EROS websites

- compositing spectral bands

- making atmospheric corrections

- quantifying land use/land cover change

- conducting supervised and unsupervised land use classification

- calculating a Normalized Difference Vegetation Index; Normalized Burn Ratio and difference Normalized Burn Ratio

- limitations of remote sensing and the importance of validation with ground reference data.

The first Summer Institutes for Cohorts 1 and 2 were two weeks in duration, a length that was shortened to ten days for Cohorts 3 and 4 as the staff became more efficient at delivering the content. The staff also learned to schedule Institutes early in the summer to provide participants more time to develop their deliverables before the start of the fall semester. The staff considered that interactions between cohorts were extremely valuable. The second Summer Institutes were designed so that Cohorts 1 and 2, then iGETT-RS Cohorts 3 and 4 could get to know one another in three days of shared sessions and field trips. This created a strain on project staff but was well worth the extra preparation.

Participants' time to work on their deliverables outside the protected domain of the Institutes was extremely limited for most, due to other demands at their home institutions. The iGETT staff always designated at least $20 \%$ of Institute hours as open work time.

The locations for the Summer Institutes were Delmar College in Corpus Christi, TX, the USGS EROS Data Center in Sioux Falls, $\mathrm{SD}$, and Northern Virginia Community College in Reston, VA, with an all-day field trip to NASA Goddard Space Flight Center in Greenbelt, MD. Nearly all iGETT-RS participants remarked on the thrill and professional value of spending time at the NASA and USGS centers.

The minimum effective ratio of staff technical support to participants was about 1:7. Staff learned the value of mixing kinds of sessions (lab activities, science presentations, and open work time) every day. The staff also learned the value of making sure participants understood the larger vision for the project of national 
workforce preparation and learned the importance of clearly stating learning outcomes for each session during the Institutes. Storing and transporting large files was an issue for some participants, so in the second iGETT project all were provided with 64 GB thumb drives loaded with the resources used during the Institutes.

The second Summer Institutes focused on:

- review of the classroom Exercises and Concept Modules developed by each participant (See, "Participant Deliverables," below);

- using participant-authored Exercises and Concept Modules to support industry-defined skills;

- program development and marketing;

- articulation with high schools and four-year colleges;

- writing successful grant proposals.

The staff used a specific pedagogical strategy during the Institutes, a series of sequential steps. In Step 1 participants followed a short presentation or demonstration. In Step 2 they did a scripted Exercise. In Step 3 they adapted an existing classroom Exercise for their own purposes, such as updating or and localizing it for their geographic area of interest. In Step 4 they developed their own classroom Exercises; and in Step 5 they taught others.

Simple feedback surveys were administered at the end of each day throughout the Institutes. Questions asked were, what was the most valuable part of the Institute for you today? What was the least valuable part? What, if anything, that was covered today would you like for us to review? Is there anything else you want us to know? Each morning, staff summarized the previous day's feedback for participants and described the ways in which their needs and concerns would be addressed. The daily feedback proved invaluable not only to meet participants' needs but also for them to bond as a community, as they heard their peers' concerns that often matched their own. They developed a sense of ownership of the Institute agendas. Only a few participants expressed discomfort with changes in the agendas that were made in response to daily feedback, preferring certainty in the details of what was coming.

Overall according to the formal exit surveys by the iGETT external evaluators, SCATE, Inc., daily feedback forms, and informal conversations, participants were extremely satisfied with the learning experiences at the Summer Institutes and with the opportunity to network with people who taught geospatial technology at other institutions. The agendas, together with the PowerPoint presentations and other resources used for conducing them, are available both on the iGETT website and upon request to the authors.

Instructional webinars were offered to participants monthly during the academic years. Webinars dealt with remote sensing special topics, geospatial frameworks to guide workforce preparation and guidance on their deliverables, and on program development. Webinar titles included Differences between Landsat missions 5, 7 and 8; Climate Change and Land Use Dynamics in the Amazon; Quantifying Shifts in Ecosystem Boundaries due to Climate Change; Teaching an eLearning Course on Remote Sensing; Occupational Codes and workforce requirements for Remote Sensing Technicians; and Geospatial Program Development in Maine by an iGETT graduate.
Partway through the period of iGETT, national guidance in geospatial workforce development was produced at the national level. The Department of Labor identified a new Occupational Code for Remote Sensing Technicians [www.onetonline.org/link/summary/19-4099.03]; NSF funded development of the Geospatial Technology Competency Model [www.careeronestop.org/competencymodel/ competency-models/geospatial-technology.aspx] and also funded the Geospatial Technology Center of Excellence (www.geotech.org) to develop both the Core Competencies for the Remote Sensing Technician and specifications for a model course, Introduction to Remote Sensing. These products and others now serve as guiding frameworks and references for students, college administrators, instructors, and employers in support of a coherent and effective national approach to geospatial technology workforce development.

In terms of participant deliverables, all participants were required to write their own classroom Exercises, and Cohorts 3 and 4 were also required to create Concept Modules for student learning. The purpose of these requirements was to support participants' learning and to build an on-line library of instructional resources that are now publicly available. The Exercises integrated remote sensing and GIS to solve specific problems of concern to society and covered a minimum of two weeks of class time. About 40 Exercises and 20 Concept Modules have been developed as of the date of this publication.

In the course of iGETT-1, the staff discovered that many participants did not know how to write curriculum. Thereafter the staff provided explicit guidelines and a generalized workflow for participant deliverables. Considerable editing by staff was required for clarity of language in some cases.

Participants chose their own topics for the Exercises. Titles include the following:

- Agriculture: Estimating Areas Suitable for Livestock Grazing in Wyoming

- Agriculture: Quantifying Areas in Cultivation in Maricopa County

- Dam Failure: Estimating Economic Losses from Potential Dam Failure in North Dakota

- Drought: Examining Drought and Land Use Conflicts in Sudan

- Energy: Identifying Biomass Sources for Local Ethanol Production in Iowa

- Fire: Evaluating Post-Fire Vegetation Recovery in San Diego County, CA

- Fire: Mapping Wildfire Burn Severity in California

- Floods: Determining Flood Risk in Iowa

- Forestry: Evaluating Insect Damage to Forest Resources in New Mexico

- Forestry: Detecting Gypsy Moth Defoliation in Virginia and West Virginia

- Geological Mapping: Using Supervised vs. Unsupervised Classification to Map Geology

- Land Use/Cover: Impervious Surfaces

- Land Use/Cover: Determining Greenway Potential in Western New York State

- Park Management: Monitoring Land Surface Heat in Yel- 
lowstone National Park

- Surface Mining: Visualizing and Analyzing Landform Change of Surface Coal Mines

- Tsunami: Investigating Tsunami Damage in Southeast Asia

- Water Quality: Comparing Land Cover Change and Stream Quality in North Carolina

- Water Quality: Comparing Urban Sprawl and Sediment Loading in the Chesapeake Bay

Participants in Cohort 3 created Concept Modules, short videos illustrating a fundamental remote sensing concept or technique, which the staff called a "Concept Module." These videos are posted on iGETT Remote Sensing Education YouTube Channel, and Cohort 4 participant-authored Modules will be found there in 2015. Titles include the following:

- Introduction to Band Combinations for Landsat Images

- Image Analysis using NDVI to Assess Vegetation Greenness

- Introduction to Solar Irradiance and Reflection

- How to use Maximum Likelihood Classification for Analyzing Remote Sensing Imagery.

- Supervised vs. Unsupervised Classification

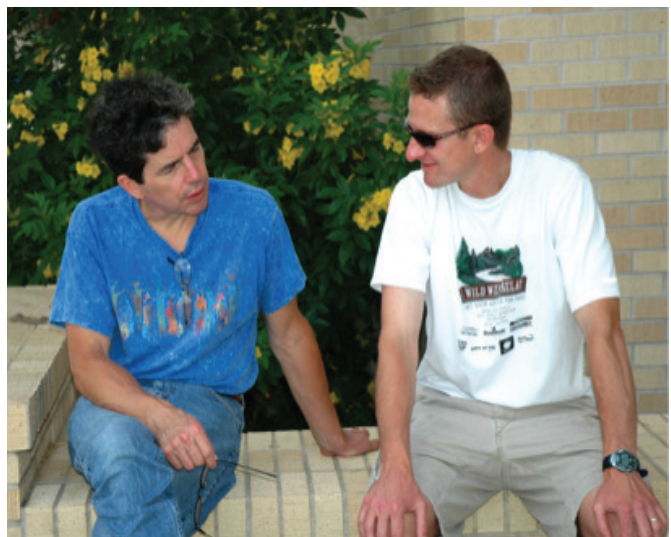

Figure 7. Richard Irish (Landsat staff, ret.) and Trent Morrell (Laramie County Community College) during a break.

Networking was a valuable aspect of the project.

Building community started even before participants met, as they were sent one-paragraph biographies and photographs of each other prior to each first Summer Institute. Certain logistical details also created a foundation for community building. Hotels were selected for their option of suites with two bedrooms and a shared living room, so that participants had instant companions who had been selected for their geographic proximity to each other. A sense of community was further developed by the demanding nature of the work during the Institutes. Struggle with shared goals and problems tended to create community. Time together apart from other obligations accomplished this as well.

Networking proved to be extremely important to the participants. In summary statements about their iGETT experience almost all indicated that the networking with this new group of colleagues and friends had been transformative. After working largely in isolation as the lone person on campus interested in geospatial technology, they now had a network of colleagues with whom they could communicate regularly. The networking led to many forms of collaboration in teaching, research, and project development.

Agendas and associated resources used during the Summer Institutes are available on the iGETT website (http://igett.delmar.edu). (Note, that URL will change in winter 2014; please contact author Allen for updated URL.)

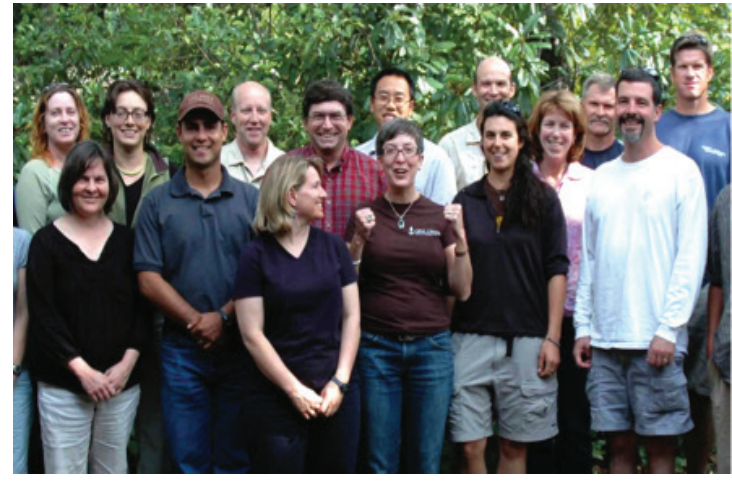

Figure 5. Dan Scollon, Shasta Community College, CA (in back row, third from right) commented, "Participation in iGETT has produced a multitude of benefits for me professionally and for my GIS program... The tangible outcomes and products from iGETT, including teaching resources, presentation materials, software and, most of all, the participant [exercises], have provided an essential starting point from which to begin offering remote sensing... at Shasta College...."

Several participants developed assumed leadership roles as a result of their work with iGETT. For example Chris Cruz and Dan Scollon together applied for and received funding from the state of California for "CalGETT," a series of workshops for natural resource managers and educators modeled after the national iGETT projects. Adam Dastrup took on the role of chair of his regional chapter of the Association for Photogrammetry and Remote Sensing. Others such as David Webb in VA and Angela Milakovic in SD had their classes collaborating on a geospatial project that combined their disciplinary perspectives. Some of the participants are bringing remote sensing to their informal geospatial education for pre-college students in workshops, summer camps, 4-H and scout activities, GIS day events at local schools and in college labs; and professional development for K-12 teachers (workshops and field trips). Jacquelin Stenehjem's Exercise, "Emergency Preparedness and Response Planning for Catastrophic Dam Failure," provided the basis for a chapter published by Esri Press.

In terms of dissemination activities, project staff and participants have presented papers, panel sessions, and exhibits about the project at several professional conferences each year. These have included the national conferences organized by the NSF Advanced Technological Education Program, the Association of American Geographers, the American Geophysical Union, the National Council for Geographic Education, the American Association for Photogrammetry and Remote Sensing, and Esri.

External evaluation was conducted by Elaine Craft and Mimi Hull of SCATE Inc., using multiple means: pre-and post- Institute on- 
line surveys; site visits at the Institutes; face-to-face interviews; email exchanges; and participation in conference calls and participant webinars.

\section{CONCLUSIONS}

From both project staff and participant points of view, iGETT has been a most successful project. Its success can be ascribed to its meeting a professional development need within two year colleges; to a high degree of commitment by the staff that encouraged in a similarly high degree of commitment by the participants; and to persistent attention to both the big picture of geospatial workforce development and attention to detail throughout project implementation. iGETT's external evaluator, Elaine Leggett Craft, SCATE Inc, remarked in a report to NSF that, "The iGETT model for preparing faculty and infusing remote sensing in geospatial education is one that works and should be replicated.... The intervention is intense (and) taps the resources of multiple government agencies, business/industry partners, and a talented and well-connected leadership team. The dedicated network of educators prepared by this project should be engaged in scaling up and expanding the impact of this work." 